\title{
Friction Stir Welding of Dissimilar Butt Joints with Novel Joint Geometry
}

\author{
D. JAYABALAKRISHNAN ${ }^{a, *}$ AND M. BALASUBRAMANIAN ${ }^{b}$ \\ ${ }^{a}$ Sriram Engineering College, Chennai, India \\ ${ }^{b} \mathrm{RMK}$ College of Engineering and Technology, India \\ (Received July 19, 201\%; revised version October 19, 201\%; in final form October 31, 2017)
}

\begin{abstract}
In this study, $1 \mathrm{~mm}$ thin sheets of AA 6061 and steel were welded by friction stir, with new joint geometry. Conventional friction stir welding develops high distortion to the specimen, particularly when the thickness is very small. In this process, friction stir welding is carried out by a tool without probe and with new joint geometry. Contrary to the conventional friction stir welding, where various tool profiles are used to obtain successful joints, the present study of investigation focused on developing a profile in the sheet metal edges to be joined. The aluminium sheet was positioned on the contoured steel sheet. Rotating tool with tilt angle was made to progress into the top sheet. Frictional heat plasticized the upper blank and the edges of the aluminium sheet were forged and extruded into the steel contour. The welding between steel and aluminium was due to a coalescence of the two materials and clamping effect was provided by the contour in the steel sheet. Tensile test was conducted to evaluate the quality of the welding along with macro and micro metallographic investigations. Further to this, scanning electron microscopy with energy dispersive X-ray and X-ray diffraction analysis have been done to understand the presence of intermetallics at the weld nugget. Tensile strength of $122.22 \mathrm{MPa}$ was achieved. Intermetallics of $\mathrm{Mg}_{2} \mathrm{Si}, \mathrm{MnAl}_{6}$ and $\mathrm{FeAl}_{6}, \mathrm{Al}_{5} \mathrm{Fe}_{2}$ was found as dominant compound at the interface. Welding of thin sheets is enhanced by form clamping and chemical diffusion bonding.
\end{abstract}

DOI: 10.12693/APhysPolA.133.94

PACS/topics: friction stir welding, aluminium, steel, joint geometry

\section{Introduction}

Friction stir welding (FSW) is a solid-state welding process which is utilized to develop blemish-free and clean welds between similar and different materials. In general, steel and aluminium custom made blanks are utilized in manufacture of auto components. Aluminium is selected for thinning out the weight of any structure, whereas steel is required for enduring more loads for the passenger's safety in automobiles. Hence the joint between steel and aluminium picks up a great deal of significance in the automobile sector.

In FSW welding, the mechanical properties of test specimen could increment with the increase of transverse speed with steady spindle speed. Adamowski et al. [1] reported that softening of the material is noticed at heat influenced zone and weld nugget of the materials which led to the failure of the joint during a tensile test. Watanabe et al. [2] reported that in the present situation, energy conservation and environmental safety are foremost issues that must be settled. Since diminishing the heaviness of vehicles is one of the proficient countermeasures against them, the use of the blend of steel and aluminum alloy has been expanding in the manufacture of vehicles. Under this circumstance, numerous trials to weld steel to aluminum alloy was carried out. In any case, sound joints have not been delivered up in conventional fusion

*corresponding author; e-mail: djayabal2001@yahoo.com welding until now, In light of the fact that hard and brittle intermetallic mixes are produced at the weld at whatever point steel was welded to aluminum. Geigera et al. [3] reported that, in order to reduce distortions occuring in the $\mathrm{Al}$ and $\mathrm{Fe}$ joints of thin metals using the conventional technique, the steel (DC 04) aluminum (AA 5182) tailored butt joints were made by the tool without the pin and a particular geometry for the sheet was chosen at the edge of the steel plate. During welding, deformed aluminum filled the cavity of steel tooth, which was because of the blending action of the tool. Examinations revealed for tensile qualities of friction stir welded at a particular temperature and strain rate for very thin rolled sheets of $0.8 \mathrm{~mm}$ in thickness of similar joints $2024 \mathrm{~T} 3$ and $6082 \mathrm{~T} 6$ as well as obtaining dissimilar joints (6082T6-2024T3). Cerri and Leo research [4] suggests that increment in temperature and an abatement of strain rate causes diminishing of flow stress. Friction stir welding was performed utilizing straight cylindrical and taper cylindrical unthreaded tools with constant process combinations. Lorraina et al. [5] concluded that the outcomes delineated that the material flows with unthreaded tool and classical threaded tools had the same effect.

An essential investigation of the FSW process was done to comprehend heat generation, heat transfer, material flow during welding, elements of tool design, defect formation, and properties of the welded materials. Nandan et al. [6] study reveals three types of flow, first one is a slug of plasticized material rotating with tool pin, further more the rotatory motion of the pin squeezes the material downward closest to the pin, and last is a relative motion between tool and workpiece. It likewise deals 
with the plastic flow of models to evaluate the velocities around the pin. Singh et al. [7] reported that post weld heat treatment decreases the strength, but enhances the percentage of elongation during the friction stir butt weld between rolled plates of 7039 aluminium alloy.

Friction stir welding of 6056-T6 aluminum alloys was provided with additional stiffener supports at both longitudinal and transverse direction to diminish the residual stress. Dong-Yang Yan et al. [8] studies indicate that distortion is found to be less in the longitudinal direction compared to the transverse direction caused by the situation of stiffeners. Examinations were made on the development of FSP zones on five distinctive tool pin profile and three different shoulder diameters in FSW of AA6061 aluminum alloy (Al-Mg-Si alloy) with a dimension of $300 \times 150 \times 6 \mathrm{~mm}^{3}$. Elangovan and Balasubramanian [9] concluded that the FSP zones were mechanically upgraded and metallurgically enhanced by a square pin tool with $18 \mathrm{~mm}$ shoulder diameter.

Four grades of aluminium sheets and dual-phase steel DP590 sheets of tailor-welded blank (TWB) were friction-stir welded by Kwansoo et al. [10] with different similar and dissimilar combination of the alloy with various thicknesses. Hardening behavior, anisotropic yielding properties and forming limit diagram were examined for both the base metal and weld zone. Aluminium alloy 3003-H18 was welded to mild steel by friction stir welding. Dehghani et al. [11] reported that by upgrading the tool rotation speed from 450 to $700 \mathrm{rpm}$ brings abatement of ultimate tensile strength from $112 \mathrm{MPa}$ to $28 \mathrm{MPa}$. Rajakumar et al. [12] concluded that AA7075-T6 joints fabricated at $1400 \mathrm{rpm}, 60 \mathrm{~mm} / \mathrm{min}$ welding speed, $8 \mathrm{kN}$ axial force and $5 \mathrm{~mm}$ pin diameter with $15 \mathrm{~mm}$ shoulder diameter have yielded higher strength.

Lap joint of A5083 aluminium alloy and SS400 steel was fabricated by friction stir welding. Kittipong Kimapong et al. [13] concluded that increase in rotational speed of the tool decreased the shear strength of the joint. The formation of the intermetallic compound $\mathrm{FeAl}_{3}$ also led to poor quality of the joint. An innovative overlap joint between aluminum alloy AA5754-H22 $2 \mathrm{~mm}$ and steel DX54 $1.5 \mathrm{~mm}$ thick was made using friction stir welding technique. A wave-shaped geometry was embossed on the steel sheet at the interface of the joint. The lateral vertices of the wave-like feature promoted the solid-state joint mechanism which led to interfacial diffusion and atomic bonding in addition to the mechanical interlocking. The probe filled the aluminum alloy in the cavities of wave shaped geometry resulting in mechanical clamping. It was reported by Sorger et al. [14] that the joint strength of about $50 \%$ of the ultimate tensile strength of the base aluminum alloy was achieved.

Transformation-induced plasticity (TRIP) 780 steel of sheet thickness $1.4 \mathrm{~mm}$ was joined with $\mathrm{Al}$ 6061-T6 sheet of $1.5 \mathrm{~mm}$ using FSW technique. Highest joint strength obtained was $240 \mathrm{MPa}$, which is about $85 \%$ of the aluminium alloy. Analysis of the interface area detailed that thin layer of intermetallic compound (IMC) $\mathrm{Fe}_{3} \mathrm{Al}$ was created due to the reaction between sheared off steel particles and aluminum matrix, which was useful to produce a sound joint [15]. FSW butt joint of $3 \mathrm{~mm}$ thick aluminum alloy AA5052 and HSLA steel was done. The formation of an IMC layer at the weld centre impacted the joint quality. Traverse speed of $45 \mathrm{~mm} / \mathrm{min}$ produced greatest joint strength of $188 \mathrm{MPa}$ which is $91 \%$ UTS of the base aluminum alloy. It was concluded by Ramachandran et al. [16] that the impact of tool traverse speed on the thickness of IMC layer resulted in high joint quality.

The influence of annealing temperature and time on joint strength during joining of aluminum alloy Al-5083 and steel St-12 using FSW was studied. Considerable joint strength was achieved by the increase of the duration of annealing treatment between temperatures of 300 and $350^{\circ} \mathrm{C}$. The authors [17] reported that the formation of IMC layer after annealing had a higher impact on strength. In the meantime, joint strength decreased with increase in annealing time at a temperature of $400^{\circ} \mathrm{C}$. FSW of aluminum alloy AA6061 and mild steel DC 04 with a thickness of about $1 \mathrm{~mm}$ was made. The authors of [18] studies indicate that heat treatment to a range of $250{ }^{\circ} \mathrm{C}$ and $450{ }^{\circ} \mathrm{C}$ resulted in a reduction of tensile strength to about $20 \%$. A fracture at the TMAZ of the aluminum side was found due to the changes in precipitation formation of the aluminum alloy caused by heat input. A maximum joint strength of $85 \%$ was achieved compared to the base aluminum alloy.

Formation of thick IMCs in the weld zone of $\mathrm{Al} 5186$ to mild steel and poor joint strength was detected at low welding speeds. Joint exhibits high tensile strength and IMC depreciation on the increase of welding speed. Dehghani et al. [19] report suggests that ultimate tensile strength was found decreased from 246 to $187 \mathrm{MPa}$, when the plunge depth was decreased from $0.4 \mathrm{~mm}$ to $0.3 \mathrm{~mm}$. Laser-assisted friction stir welding of $3 \mathrm{~mm}$ thick 6061-T6 aluminum alloy and Q235 steel was carried out. The principal elements identified were the offset distance, type and thickness of the inter-metallic compound layer. Xinjiang Fei et al. [20] studies indicate that the grain size gradually reduces from HAZ towards weld nugget. Finer grains were observed at weld nugget.

It was seen in FSW of aluminum alloy 6063-T5 and AISI steel SAE 1020 that the sticking of aluminum particles to the tool and all the subsequent problems were because of partial melting. Grain growth phase was reported by Torre.s Lópeza et al. [21] at HAZ and drastic rotation of grains at TMAZ and recovery and dynamic recrystallization at blend zone. Aluminum alloy 6061-T6 alloy to trip steel was joined effectively and a highest tensile strength of $85 \%$ of the base metal was accomplished. Higher rotational speed and larger tool offset elevated the overall temperature distribution in the weld. Xun Liu et al. [22] reported that the overall temperature dissemination at the weld nugget is increased with the increase of tool rotational speed and its offset has also influenced the composition of IMC layer. Scanning electron microscopy results showed that the nugget was composed of sheared 
steel sections in the aluminum matrix composite which acted as a reinforcement surrounded with intermetallic particles. In the conventional process, molten phases deliver excessive heat input, which alters the microstructure of the materials. This leads to mixed phases which are brittle and hard to machine. On the other hand, this may also induce hot cracks due to shrinkage. Conventional friction stir welding also develops high distortion to the specimen, particularly when the thickness is very less. To overcome these problems, an attempt was made to develop a joint geometry (edge preparation) of the base materials, so that the above mentioned problems could be reduced.

In the present investigation, the steel sheet was made with contoured geometry and aluminium sheet with nor- mal straight edge. The aluminium sheet was placed over the contoured steel sheet. Rotating tool with tilt angle was made to progress into the top sheet. Frictional heat plasticized the upper blank and the edges of the aluminium sheet were forged and extruded into the steel contour. Joint strength was enhanced by form clamping and friction which occurred between the two materials.

\section{Experimental}

The examined materials were AA 6061 and low carbon steel of $1 \mathrm{~mm}$ sheet thickness. The chemical composition and mechanical properties of the base material under investigation is depicted in Table I and Table II, respectively.

Chemical composition [wt\%] of base metal under investigation.

TABLE I

\begin{tabular}{c|c|c|c|c|c|c|c|c|c|c|c|c|c|c|c}
\hline \hline & \multicolumn{10}{c}{ Element } \\
\cline { 2 - 14 } Material & $\mathrm{Si}$ & $\mathrm{Fe}$ & $\mathrm{C}$ & $\mathrm{Cu}$ & $\mathrm{Mn}$ & $\mathrm{Mg}$ & $\mathrm{Cr}$ & $\mathrm{Ni}$ & $\mathrm{Zn}$ & $\mathrm{P}$ & $\mathrm{Ti}$ & $\mathrm{Pb}$ & $\mathrm{S}$ & $\mathrm{Sn}$ & $\mathrm{Al}$ \\
\hline AA6061 & 0.430 & 0.155 & & 0.04 & 0.029 & 1.33 & 0.140 & $<0.002$ & 0.001 & - & 0.014 & $<0.005$ & - & $<0.005$ & $\mathrm{bal}$. \\
steel & 0.07 & bal. & 0.056 & - & 0.524 & - & - & - & - & 0.026 & - & - & 0.001 & - & -
\end{tabular}

Mechanical properties of cold rolled steel.

TABLE II

\begin{tabular}{|c|c|c|c|c|}
\hline \multirow[t]{2}{*}{ Material } & Tensile & Yield & \multirow{2}{*}{$\begin{array}{c}\text { Elongation } \\
{[\%]}\end{array}$} & \multirow{2}{*}{$\begin{array}{c}\text { Vickers } \\
\text { hard. [HV }\end{array}$} \\
\hline & strength & [MPa] & & \\
\hline $\begin{array}{c}\text { AA6061 } \\
\text { steel }\end{array}$ & $\begin{array}{l}220 \\
320\end{array}$ & $\begin{array}{l}110 \\
210\end{array}$ & $\begin{array}{l}19 \\
37\end{array}$ & $\begin{array}{c}65 \\
118\end{array}$ \\
\hline
\end{tabular}

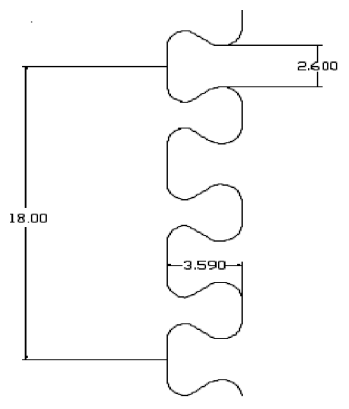

Fig. 1. Edge geometry.

Welding parameters and tool dimensions.

TABLE III

\begin{tabular}{c|c}
\hline \hline Process parameter & Values \\
\hline rotational speed $[\mathrm{rpm}]$ & 2200 \\
welding speed $[\mathrm{mm} / \mathrm{min}]$ & 60 \\
axial force $[\mathrm{kN}]$ & 12.5 \\
diameter of tool $[\mathrm{mm}]$ & 15 \\
tool tilt angle $\left[{ }^{\circ}\right]$ & 2
\end{tabular}

Both the plates of low carbon steel and AA 6061 aluminium alloy were welded by friction stir welding. The steel sheet of $130 \times 100 \times 1 \mathrm{~mm}^{3}$ and aluminium sheet $180 \times 120 \times 1 \mathrm{~mm}^{3}$ were used for the joining process. Edge geometry of the steel sheet was obtained by plasma cutting (Fig. 1). Trial runs were conducted by using various process parameters in order to identify the optimum process parameter to maximize the performance of the joint. The joint ready for joining is seen in Figs. 2, 3. Process parameters used for friction stir welding of the dissimilar materials under investigation are presented in Table III. The joint accomplished between aluminium and steel joints was due to mechanical clamping as well as chemical bonding.

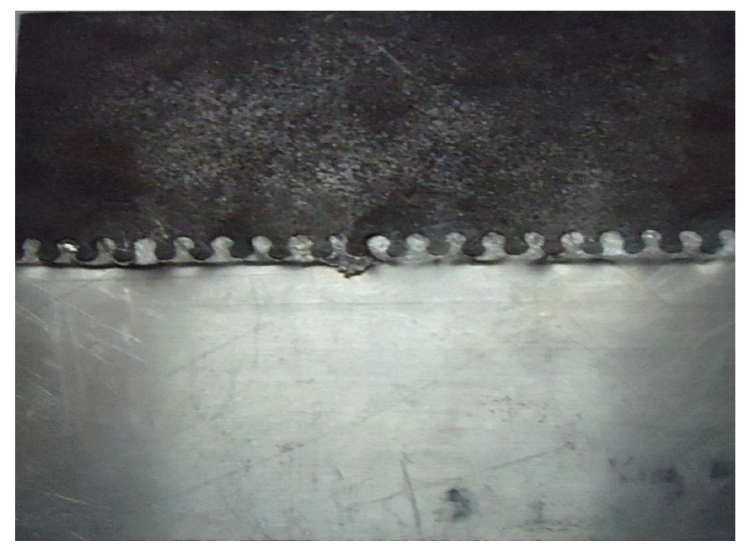

Fig. 2. Bottom surface of the joint.

A newly developed tool for FSW was made of HSS material as shown in Fig. 4, which had no probe. Using the above tool, FSW was performed on aluminum alloy with low carbon steel sheets using fixture (Fig. 4), which was exclusively made for thin sheets on a 10 ton hydraulic FSW machine. Trial run was conducted using various process parameters such as welding feed between 32 and $160 \mathrm{~mm} / \mathrm{min}$, rotational feed from 400 to $2200 \mathrm{rpm}$ and the tilt angle of $2^{\circ}$ as tabulated in Table III and finally, perfect welding was carried out with the welding speed of $2200 \mathrm{rpm}$, transverse feed of $32 \mathrm{~mm} / \mathrm{min}$, tool tilt angle 


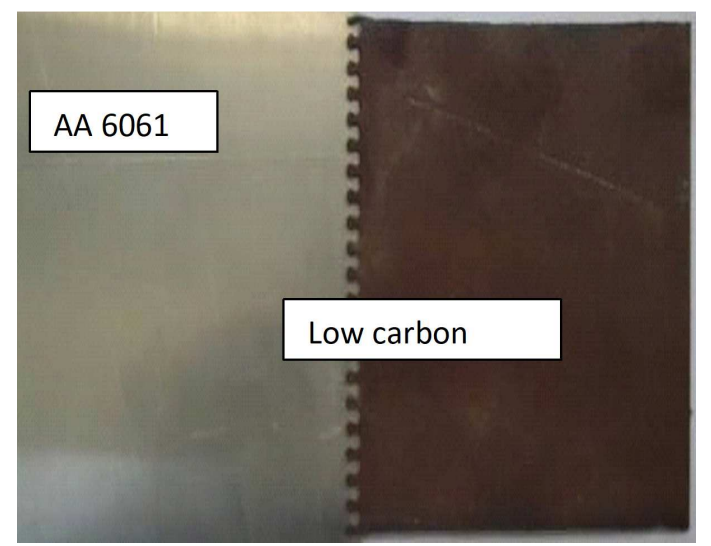

Fig. 3. Top surface of the joint.

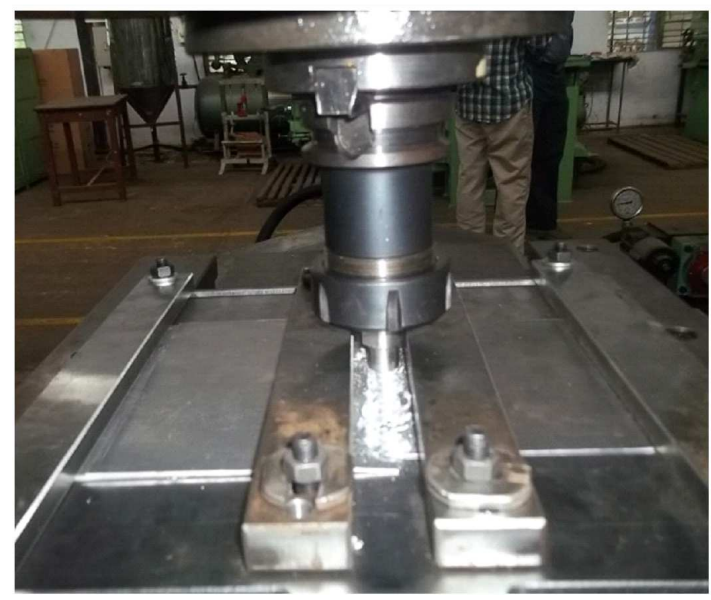

Fig. 4. Welding fixture with probeless tool.

of $2^{\circ} / \mathrm{s}$ and $12.5 \mathrm{kN}$ axial force. During the conventional friction stir welding, more heat was generated, while in our investigation, a new geometry was created on the weld specimen which reduced the heat generated at the weld interface. The aluminium material flowed plastically into the steel contours. There existed two different

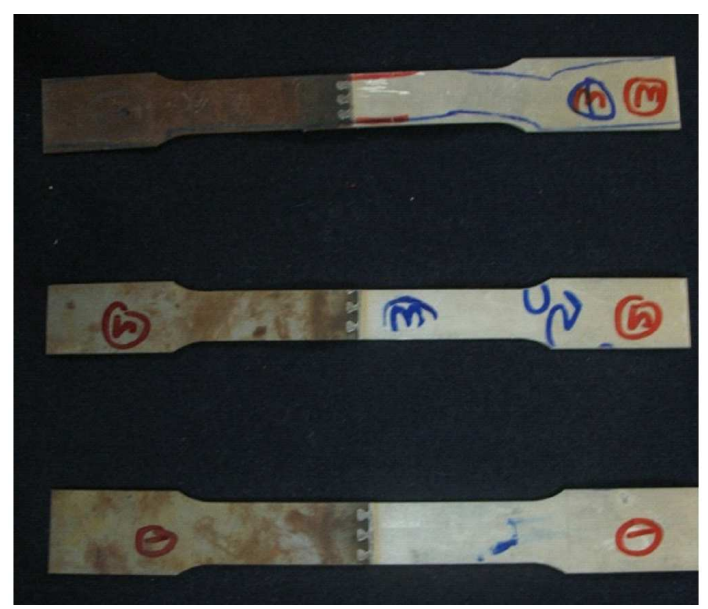

Fig. 5. Tensile test specimen.

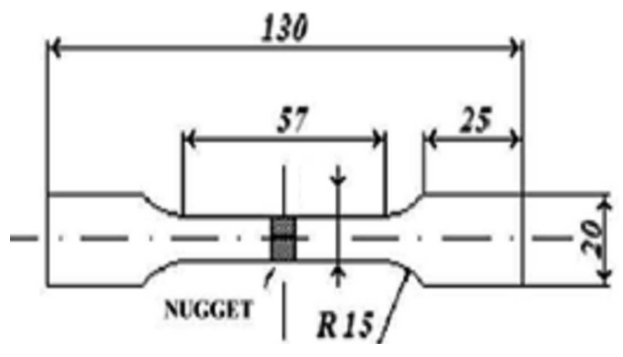

Fig. 6. Tensile test specimen dimensions.

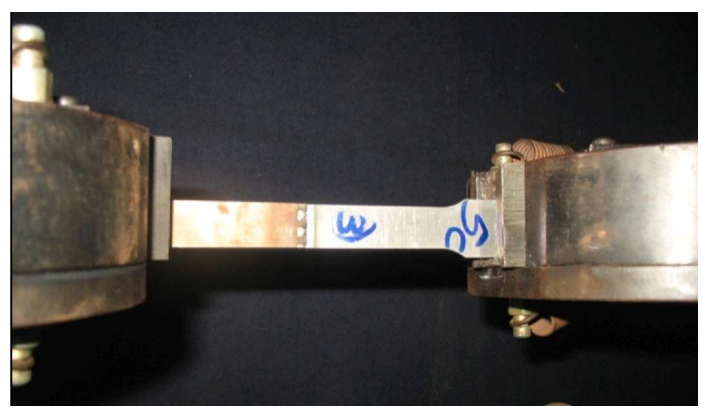

Fig. 7. Specimen under tensile test.

activities during the welding process. One activity deformed both the aluminium and steel material and caused the material flow and settle inside the spline which was created on the edge of the steel. Secondly, a mechanical locking existed between the two materials.

Specimens for tensile testing were prepared by wire cut EDM as seen in Figs. 5, 6. Tensile tests had been conducted to understand the strength of the joints using the facility as seen in Fig. 7. Here no standards were preferred to prepare the tensile specimen, because the gauge length was not a criterio and aim of the investigation was to find the maximum transferable force during breaking for the constant number of teeth. Constant three whole teeth of aluminium and one half steel tooth either side of end of aluminium tooth was cut to find the maximum transferable force which came to approximately $18 \mathrm{~mm}$ width for gauge length. In addition to the tensile test, metallographic investigations had been carried out to characterize the joint.

\section{Results and discussion \\ 3.1. Effect of base metal edge on tensile strength}

In the current investigation, the connection between steel and aluminium was due to mechanical fastening as well as chemical bonding. In the present scheme of investigation, a new geometry was prepared on the edge of steel with $B$ spline geometry (Fig. 1) specimen to join with aluminium for fabricating aluminium steel dissimilar joint. In the conventional form of FSW, stirring action of the tool will induce the material to flow plastically and the joint will be configured. But to overcome difficulty occurring in welding thin sheets, a new joint geometry was experimented. In this current study 
it was understood that the amount of teeth would increase the number of interactions and thereby it would increase the transferable force. The tensile strength depends upon the numbers of contour considered for the width of gauge length. For the above test, three contours were considered. Joints made with less axial force did not weld properly or got separated after welding. Since the tool without pin was used, more axial force was required to produce sound joints. Since the tool used had a tilt angle and did not have a probe, the tool wear was considerably minimum. It was learnt that the successful welding of the deep drawing steel DC04 and the aluminium alloys AA5182 and AA6016 in two hybrid combinations were achieved. The maximum strength obtained in a friction stir knead welded tailored hybrids using a steel support was slightly above $100 \mathrm{MPa}$. Later on, a nickelalloy based support had been utilized to limit the heat flux into the clamping device and to achieve high quality joints. In this case a maximum transferable force of more than $150 \mathrm{MPa}$ was obtained, which was $50 \%$ higher than the initial condition with the steel support.

In this process, apart from material flowing plastically, mechanical locking took place between the geometry in the steel and aluminum, which caused chemical bonding on one hand and mechanical anchoring on the other hand, resulting in defect free joints. The maximum strength observed by tensile tests of friction stir welded tailored hybrids was slightly above 122.22 MPa. Elongation in the order of $27.6 \%$ was observed during the tensile test. In addition to tensile tests, metallographic examinations were done in order to retrieve more information pertaining to the influence of the process parameters on the microstructure of the weld nugget.

\subsection{Microstructure investigation}

The samples were prepared for metallographic investigation by polishing and etching with nital and kellar reagent solution. Figures $8-10$ show the parent material microstructure of the low carbon steel and AA 6061 aluminium alloy. The microstructure had shown fine eutectic particles dispersed in aluminium solid solution. The eutectic phase was $\mathrm{Mg}_{2} \mathrm{Si}$ and some $(\mathrm{Mn}, \mathrm{Fe}) \mathrm{Al}_{6}$ precipitates were also present. Figure 9 shows the low carbon steel matrix which was normalized to give uniform grains of pearlite in ferrite matrix. The low carbon side had shown heat affected zone with larger grains of pearlite, while the aluminium alloy was unaffected due to higher plasticity. The presence of the precipitates $\mathrm{Mg}_{2} \mathrm{Si}, \mathrm{MnAl}_{6}$ and $\mathrm{FeAl}_{6}, \mathrm{Al}_{5} \mathrm{Fe}_{2}$ as dominant compound which was due to the diffusion of aluminium constituents to the steel zone. This had resulted in the substantial diffusion bonding. No zone depicted the presence of elemental iron and aluminium. This was also confirmed through X-ray diffraction analysis (XRD) shown in Fig. 11. The XRD analysis was taken along the interface zone of steel and AA 6016 had shown the intermetallic compounds formed during the diffusion process. The compounds formed were $\mathrm{Al}_{5} \mathrm{Fe}_{2}$ as dominant compound. The compounds had been formed due to the diffusion of aluminium constituents to the steel zone. This had resulted in the substantial diffusion bonding.

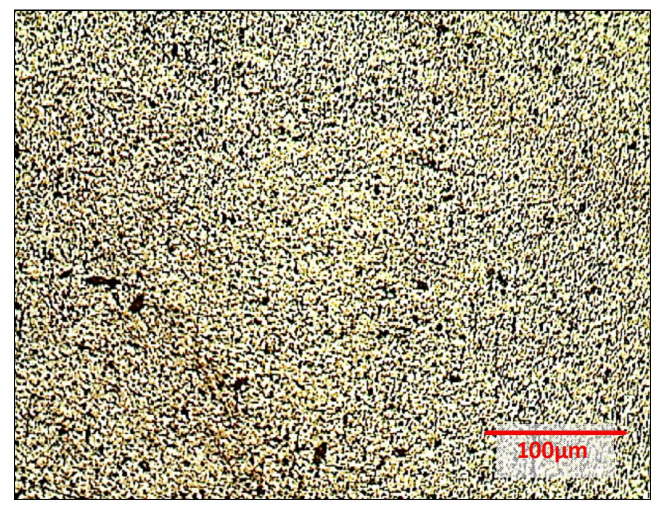

Fig. 8. Microstructure of AA6061.

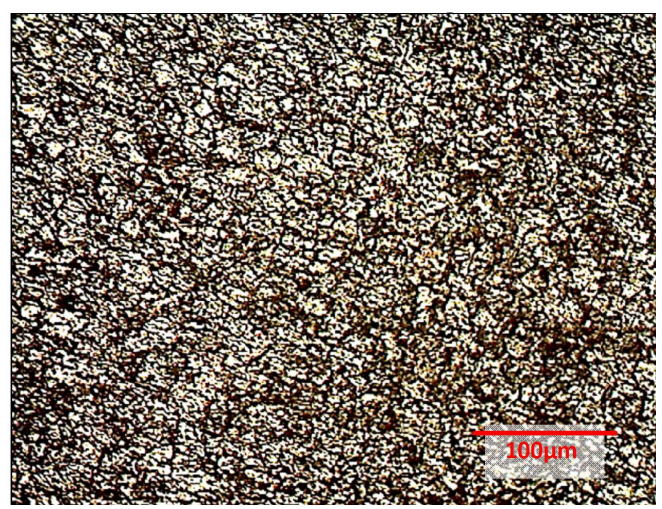

Fig. 9. Low carbon steel microstructure.

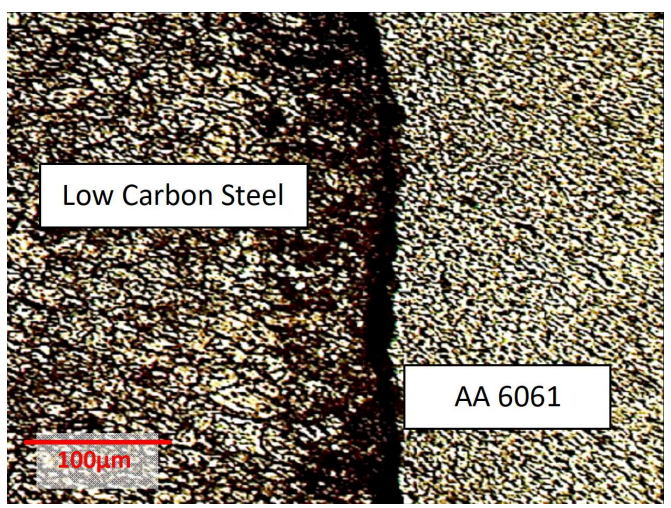

Fig. 10. Interface zone of aluminium alloy and low carbon steel.

A macroanalysis of the weld interface which had shown mechanical fastening and chemical bonding is produced in Fig. 12. The SEM image in Figs. 13, 14 show the interface zone of steel and AA6016 aluminium alloy. The proximity of the bond had shown the effect of diffusion bonding. The image shows the presence of the constituents of aluminium in steel matrix and vice versa. 
The microphotography shows the change in microstructure morphology at the steel interface and aluminium interface. This resulted in effective bonding through diffusion of constituents one into the other.

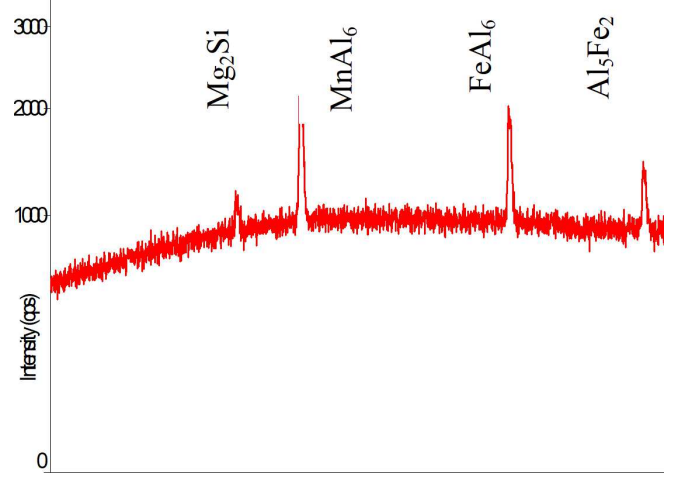

Fig. 11. X-ray diffraction analysis.

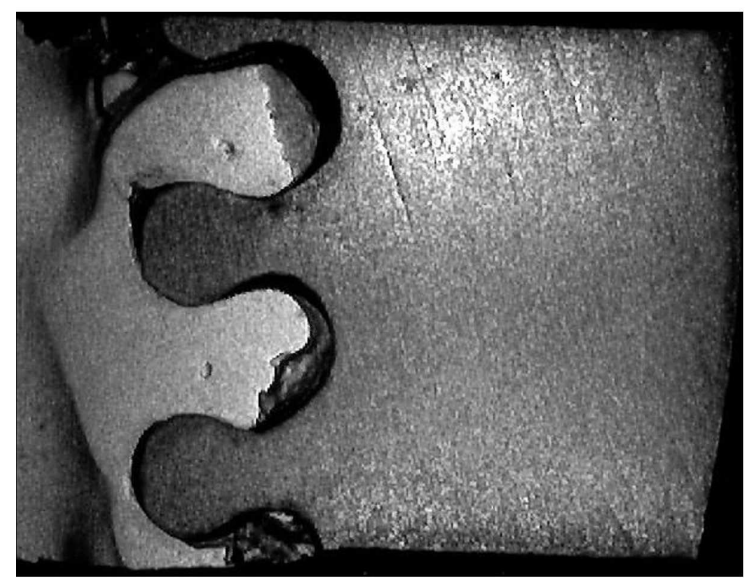

Fig. 12. Macroimage of the weld interface.

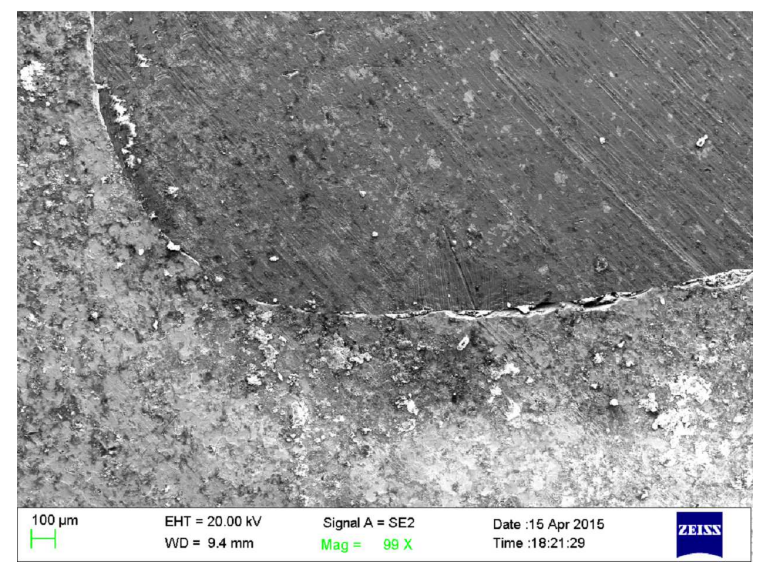

Fig. 13. Interface of steel and aluminium.

Changes in hardness of steel and aluminium were observed corresponding to the area of transition of the tool. The hardness profile of the steel was observed to vary from $176 \mathrm{HV}$ at the joint interface to $123.9 \mathrm{HV}$ in the

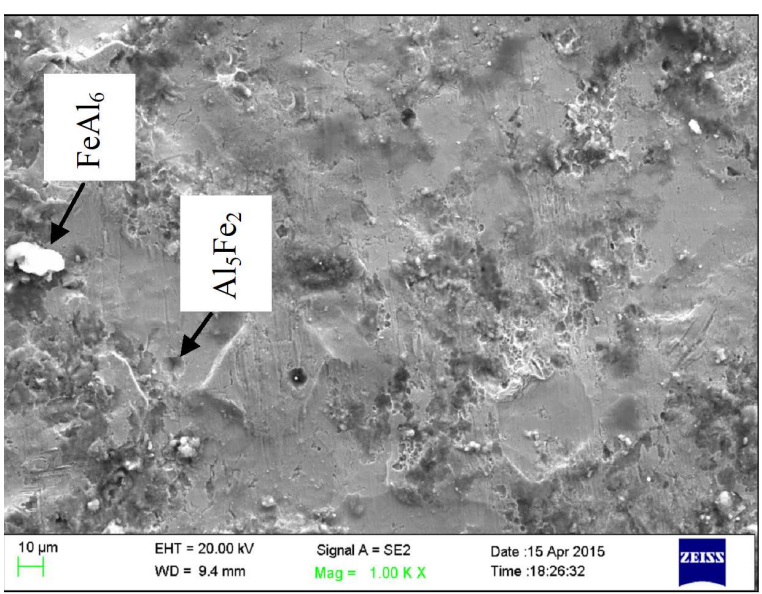

Fig. 14. SEM image showing the intermetallic compounds.

top region away from the joint interface. The hardness values were found to increase from top to bottom and right to the joint force (left). Hardness profile of the aluminum followed a pattern typical of heat-treatable aluminum alloys by having a distinct reduced hardness region corresponding to the thermoaffected zone (TMAZ) of the weld. Hardness levels were found to be the lowest in the stir zone ranging between 54.4 and $69.1 \mathrm{HV}$. The hardest region of the aluminum workpiece was $79.1 \mathrm{HV}$ at the bottom surface of the joint away from the interface. The change observed in the highest hardness region of the aluminum and steel were mostly due to diverse heat transfer rates observed in both the materials under investigation as shown in Fig. 15. Increase of hardness in the weld interface of steel was found due to the presence of steel fragments which was pulled off from a steel blank by the tool during stirring and might also be due to edge profile made by plasma, which has caused an increase of temperature at the interface. Decrease of hardness in certain regions of aluminium interface was due to the amount of precipitates originating below threshold temperature. Increase of hardness in certain regions of aluminium interface was due to reduction in the size of impurities present which may be due to stirring action of the tool.

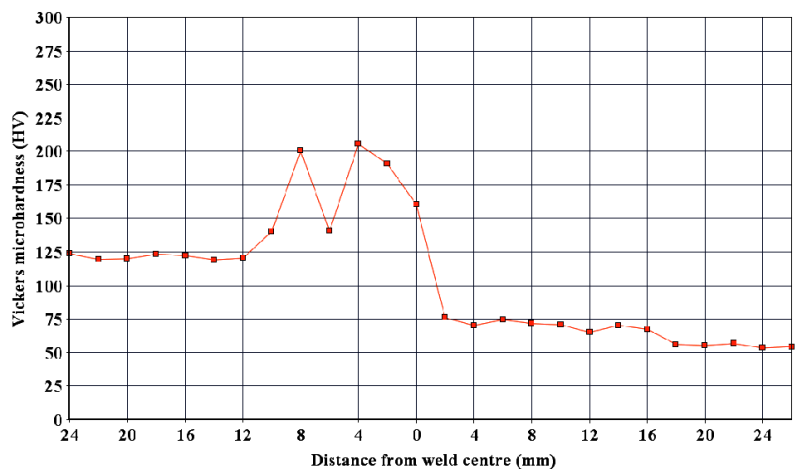

Fig. 15. Hardness survey. 


\section{Conclusions}

The observations and inference made from the present investigations are the following.

1. In order to overcome the distortion normally faced while welding of thin sheets and eliminate the difficulty in friction stir welding of thin sheets of dissimilar steel and aluminium joints, new edge geometry was used. Successful welding had been carried out for the same.

2. The maximum force obtained under tensile test was 122.22 MPa with considerable elongation in the range of $27.6 \%$. Welding was accomplished by mechanical clamping as well as chemical bonding.

3. Significant influence on the joint strength is observed due to joint geometry at the interface of the joint and more than $70 \%$ transferable force was due to form clamping and remaining because of chemical diffusion bonding.

4. At the interface, low carbon steel side had shown heat affected zone with larger grains of pearlite with higher hardness and the aluminium alloy side was not affected due to higher plasticity at the zone.

5. Metallographic interpretation had shown the deformation of the aluminium alloy into the steel contour due to stirring effect.

\section{References}

[1] J. Adamowski, M. Szkodo, J. Achiev. Mater. Manufact. Eng. 20, 403 (2007).

[2] T. Watanabe, H. Takayama, A. Yanagisawa, J. Mater. Process. Technol. 178, 342 (2006).

[3] M. Geiger, F. Micari, M. Merklein, L. Fratini, D. Contorno, A. Giera, D. Staud, Int. J. Mach. T. Mfr. 48, 515 (2008).
[4] E. Cerri, P. Leo, Mater. Des. 31, 1392 (2010).

[5] O. Lorraina, V. Favier, H. Zahrouni, D. Lawrjanie, J. Mater. Process. Technol. 210, 603 (2010).

[6] R. Nandan, T. DebRoy, H.K.D.H. Bhadeshia, Prog. Mater. Sci. 53, 980 (2008).

[7] R.K.R. Singh, C. Sharma, D.K. Dwivedi, N.K. Mehta, P. Kumar, Mater. Des. 32, 682 (2011).

[8] Dong-Yang Yan, Aiping Wu, J. Silvanus, Qingyu Shi, Mater. Des. 32, 2284 (2011).

[9] K. Elangovan, V. Balasubramanian, Mater. Des. 29, $362(2008)$.

[10] Kwansoo Chung, Wonoh Lee, Daeyong Kim, Junehyung Kim, Kyung-Hwan Chung, Chongmin Kim, K. Okamoto, R.H. Wagoner, Int. J. Solids Struct. 47, 1048 (2010).

[11] M. Dehghani, A.A. Akbarimousavi, A. Amadeh, Trans. Nonferrous Met. Soc. China 23, 1957 (2013).

[12] S. Rajakumar, C. Muralidharan, V. Balasubramanian, Mater. Des. 32, 535 (2010).

[13] Kittipong Kimapong, T. Watanabe, Mat. Trans. 40, 835 (2005).

[14] G. Sorger, Hao Wang, P. Vilaça, T.G. Santos, Weld World 61, 257 (2017).

[15] Shuhuai Lan, XunÂA Liu, JunÂ Ni, Int. J. Adv. Manufact. Technol. 82, 2183 (2016).

[16] K.K. Ramachandran, N. Murugan, S. Shashikumar, Archiv. Civil Mech. Eng. 15, 822 (2015).

[17] M. Movahedi, A.H. Kokabi, S.M. SeyedReihani, W.J. Cheng, C.J. Wang, Mater. Des. 44, 487 (2013).

[18] C. Mertin, A. Naumov, L. Mosecker, M. Bambach, G. Hirt, Key Eng. Mater. 611-612, 1429 (2014).

[19] M. Dehghani, A. Amadeh,.A.A. Akbari Mousavi, Mater. Des. 49, 433 (2013).

[20] Xinjiang Fei, Xiangzhong Jin, Ying Ye, Tengfei Xiu, Hongliang Yang, Mater. Sci. Eng. 653, 43 (2016).

[21] E.A. Torres López, T. López, A.J. Ramirez, Weld. Int. 29, 689 (2015).

[22] Xun Liu, Shuhuai Lan, Jun Ni, Mater. Des. 59, 50 (2014). 